\title{
University libraries in the digital era
}

\section{Citation}

Courtney, Kyle, and Emily Kilcer. "University libraries in the digital era." In Research Handbook on Digital Transformations: Research Handbooks in Business and Management series, eds. F. Xavier Olleros and Majlinda Zhegu, 135-159. Cheltenham, Gloucestershire: Edward Elgar Publishing, 2016.

\section{Permanent link}

http://nrs.harvard.edu/urn-3:HUL.InstRepos:38482466

\section{Terms of Use}

This article was downloaded from Harvard University's DASH repository, and is made available under the terms and conditions applicable to Other Posted Material, as set forth at http:// nrs.harvard.edu/urn-3:HUL.InstRepos:dash.current.terms-of-use\#LAA

\section{Share Your Story}

The Harvard community has made this article openly available.

Please share how this access benefits you. Submit a story.

Accessibility 


\section{University libraries in the digital era ${ }^{1}$}

Kyle K. Courtney, Copyright Advisor, Harvard University

Emily Kilcer, Project Coordinator, Harvard University

Office for Scholarly Communication

The library finds itself navigating a challenging transition at the dawn of a digital era: 2013 marked the fourth consecutive year in which more than 40 percent of libraries in the United States experienced a decrease in funding. The university library is no stranger to operating under financial constraints; major university library systems at Harvard, Columbia, Chicago, and more, have undergone similar cuts and reorganizations. These changes are being driven in part by the new ways in which people interact with information. It is this chapter's argument, however, that the digital age will not mark another era of decline for libraries. In fact, with the special place university libraries have traditionally held in law, policy, and pedagogy, the university library is now poised to be on the forefront of the twenty-first-century digital movement as it harnesses its staff, collections, and expertise to provide next-generation support for research, teaching, and access. The topics in this chapter-collection development, modern library space, law and policy, open access, and collaborative case study programs -are considered as representative of some of the most critical themes for a university library to embrace in the modern era.

As technology continues to impact the delivery of information services, traditional academic library systems have shifted - and have come to embrace - their role in the digital era. University libraries have progressed from focusing on the management of physical assets (books, journals, etc.) to transforming this content and the library's related services into rich digital objects to support teaching, learning, and research. We begin with a brief look at the movement through three phases of the university library's mission: 1) "just in case" collection development (print focused), 2) "just in time" research (print and online hybrid), and, last, 3) "on demand" research (online, with enhanced digitization technology).

\footnotetext{
${ }^{1}$ The authors wish to thank Lily Troia, Suzanne Wones, Lisa Brem, and Ellen Finnie Duranceau for their invaluable comments, research, and advice.
} 
The relationship of libraries to scholarship and research is often charted back to the Royal Library of Ashurbanipal in Nineveh, Mesopotamia, which, at its height around eighth century B.C., was believed to have held around 25,000 meticulously organized and arranged clay tablets on a variety of subjects, many of which were translated for increased access (Dunlap, 1972, p. 11-15). The university library first appeared during the Byzantine reign under Constantine in the fourth and fifth centuries A.D. (Harris \& Johnson, 1984, p. 63), and in the Moslem Empire from 650 A.D. to 1000 A.D., in cities such as Baghdad, Cairo, and Cordoba (Dunlap, 1972, p. 54-61).

Following the fall of the Roman Empire, libraries in Western Europe saw a sharp decline in the early Middle Ages, with the monastic tradition serving as the primary preserver of written culture (Rubin, 2010, p. 42). By the late Middle Ages, however, the region witnessed a surge in economic development and improved social conditions, and in the mid-thirteenth century the University of Paris, followed by Oxford and Cambridge, established libraries in support of the institutions' educational missions (Shera, 1976, p. 24).

In the United States, modest university libraries at Harvard and Yale were established during the colonial period, though collections remained small until the mid-nineteenth century. Four significant events during this period that helped foment the development of American research universities had an irrevocable effect on academic libraries in the United States (Rubin, 2010, p. 50): expansion of the curriculum beyond the Classics to include natural sciences, and, thus, methodologies that shifted students into laboratory settings; passage of the Morrill Land Grant Act in 1862 by the Federal Government, allocating public land to establish state universities focused on applied sciences and technology (Atkinson \& Blanpied, 2008, p. 30-40); proliferation of the German seminar model over oral recitation traditions, resulting in new demand for scholarly and historical publications in the United States (first explicitly adopted by John Hopkins University upon its formation in 1876; Weiner, 2005); and professionalization of librarians, codified by the formation of the American Library Association (ALA) in 1876 and the first library education program, established by Mevil Dewey at Columbia University in 1887 (Alston Jones, 1989, p. 269). 
The ability of academic libraries to promote scholarship and research required a dramatic expansion of holdings and the establishment of a collection model that would support advanced exploration across a spectrum of subject areas. US library history credits Charles C. Jewett's report for the Smithsonian Institution in 1850 as introduction of the first collection development framework. Jewett's checklist system assessed gaps in collections in response to the realization that academic library holdings were sorely lacking materials adequate to support historical scholarly research (Johnson, 2004, p. 269).

Despite an increased interest in academic research, most of the funding used to expand library collections came from private endowments and state allocations until after World War II, when federal funding for research and development became a priority under Franklin D. Roosevelt's tenure as President of the United States (Weiner, 2005, p. 34). In the 1950s and 1960s collection development moved beyond examining adequacy to developing individual collections. As such, the selection of materials emerged as a primary role of academic librarians, and, along with increased budgets, academic libraries began to embrace a "just in case" framework for collection development. This model relied heavily on bibliographer expertise and attempted to obtain all potentially useful print materials in anticipation of future research needs.

Print-based collection development in university libraries in the latter half of the twentieth century adopted myriad analytical tools for assessing holdings, strategically planning acquisitions, and evaluating usage patterns. With the information explosion of the 1970s, librarians recognized the need for concerted "weeding" and a more targeted collection methodology, such as collection-level setting and the Conspectus model. The Research Library Group (RLG) first applied the latter model in the United States in 1982 when they initiated the National Shelf List Count, which attempted to compile a list of academic holdings organized by Library of Congress classification number (Bushing, 2001). In 1985 the Association of Research Libraries Office of Management Studies released the Manual for the North American Inventory of Research Library Collections, promoting the Conspectus method for comparing and evaluating collections (Palais, 1987, p. 8). 
Similarly, the course analysis method, which saw numerous incarnations from the late 1960s through early 1980s, assigned Library of Congress classification numbers to course offerings, compared the assignments to data regarding holdings in those same areas, and applied statistical analysis to determine subject area strengths and weaknesses (Palais, 1987, p. 9). Automated acquisitions programs developed by vendors provided libraries with detailed reports and integrated ordering systems aimed at streamlining collection development for ease and efficiency (Rubin, 2010, p. 232). Additionally, an emphasis on diversity in acquisitions and holdings began to receive traction in the early 1980s (American Library Association, 2014), buoying the movement toward inclusive, comprehensive collections.

Faculty input has long been integral to collection development, though traditionally acquisitions have been based on the size of the academic department. As course analysis became more nuanced, direct faculty involvement was recognized as paramount to the methodology's success. This was especially true as academic scholarship began to embrace interdisciplinary approaches and clear delineations among research subjects were blurred. These developments encouraged a collection assessment model based upon usage and circulation information, rather than predictive determinations (Chung Wilson \& Edelman, 1996, p. 199) - a framework that was undoubtedly appealing to administrators as academic libraries faced severe budget cuts in the 1990s and beyond.

This shift to a use-determined model for acquisitions eschewed long-term planning for purchasing decisions and marked the emergence of a new collection development philosophy. Inter-institutional cooperation became more prevalent both in response to the need for efficient access over ownership and as selection criteria was dramatically altered by the influx of electronic resources (Schamber, 1996). While hardly a new practice in the United States, the 1990s saw a steady increase in interlibrary loan activity, facilitated by online catalogs and codified by the Interlibrary Loan Committee of the ALA's Reference and User Services Association in 1994 (American Library Association, Interlibrary Loan Committee, Reference and User Servers Association, 2008). Academic librarians were quick to acknowledge the Internet and World Wide Web's immeasurable impact on information retrieval, and proposed a vision for collection development in the mid-90s that recognized both the increasing futility of 
attempts to acquire and catalog in a comprehensive manner and the necessity of incorporating electronic resources and consortia coordination (Martin, 1996, p. 291).

Academic librarianship in the twenty-first century embraced this hybrid print-online approach to research support and developed complex portal systems that connected users to an expanded network of resources available via the burgeoning information marketplace, myriad channels of scholarly communication, and cooperative programs (Shreeves, 2003, p. 66). The emerging digital environment and reality of diminished budgets demanded that librarians reevaluate not just collection development, but also the allocation of all resources, including staffing and facilities organization. The result was movement from a focus on information delivery to a suite of research services (Pritchard, 2008, p. 219). Implicit in this shift was an emphasis on unique and niche collections appealing to specific, often localized patron demographics (Sandler, 2006, p. 241), which precipitated a new system of user- or demandbased acquisitions.

The movement away from a bibliographer-driven collection development plan to one in which the user serves as the selector is referred to as patron-driven acquisition (PDA). This reflects the transition from a "just in case" library collection philosophy to a "just in time" model, made possible by the immediacy afforded by the digital era. Initial PDA systems developed out of circulation rate studies and looked to interlibrary loan request statistics to guide user-initiated acquisition processes (Arougheti, 2014). By 2009 PDA was a widely accepted methodology, and by 2011 it was a frequent centerpiece at academic librarian conferences, reflecting its established position in collection development policy and procedure (Walker, 2102, p. 126). Academic libraries found an amenable partner in vendors, who helped create approval plans that allowed for the automatic purchase of user-requested items within a range of established parameters (Arougheti, 2014).

Over the past five years, patron-driven acquisition has come to be seen as merely one, albeit major, component necessary for implementing an on-demand information delivery system that has been shaped by fiscal difficulties, the changing supply-chain landscape, and rapid technological developments (Jones, 2011, p. 767). In a 2011 report, Redefining the Academic Library: Managing the Migration to Digital Information Services, produced by the 
Education Advisory Board (Pelish, 2011), author Matthew Pelish predicted that by 2015, 90 percent of library patrons would go elsewhere for information, traditional librarians would be replaced by newly focused professionals, and most library space would be utilized for nonbook-related activities and services. Pelish examined the rising costs of serials and the shift toward a "value centric" model that demands academic libraries account for their worth via measurable outcomes, such as student retention rates or faculty grant dollars. He itemized ways in which successful libraries have and will continue to navigate this seismic shift from proprietary collections to digital services, building off of the just-in-time systems that are ubiquitous in contemporary academic libraries. Such efforts include supporting open access publications, reducing collections while expanding access to ebooks and shared repositories, and converting physical space to support active, maker-style services and on-demand research assistance (Pelish, 2011).

Pelish's predictions well reflect the state of academic libraries today, which are marked by users' expectations regarding remote services, the rise of openings for technical services and digital humanities librarians, and the rapid ascendancy of the makerspace movement. These movements also reflect a change in the way students "use" a library. Academic librarians are synthesizing the on-demand research needs of their constituency with the on-demand capacity the digital era affords. Examples like the University of Wyoming's Wool Laboratory Collection, which features web-supported video resources, digitized publications, and oral histories that have been gathered together as a web-based multimedia tool, exhibit the creative potential of digital technology currently being harnessed by academic librarians (Grover, Gerre, Achleitner, \& Visnak, 2015, p. 122). Additionally, academic librarians are curating local research collections, becoming publishers of their institution's scholarship, and managing datasets in institutional repositories - efforts all aimed at long-term preservation and access (Grover et al., 2015).

With shrinking budgets and the reality of the Internet as the first stop for information retrieval, the academic library's survival has required a savvy, adaptable strategy, and a willingness to embrace digital curation over print ownership. The surge in online learning programs has led to drastic adjustments in library practice and the recognition that traditional models of information literacy instruction no longer reflect the current state of user needs 
(Kammerlocher, Couture, Sparks, Harp, \& Allgood, 2011, p. 394). Academic librarians have been key players in instructional technology, web-supported module-style learning objects, and learning management systems (LMS), which deliver the on-demand research and instruction assistance for students they have come to expect (Kammerlocher et al., p. 393). Amid the transformation to an era of near-complete digital integration, this ability to provide enhanced, immediate support positions library professionals as leaders in the future of information services, scholarship, and learning.

\section{University Library Space}

These changes described above, especially in areas of academic teaching and learning, have been influenced and enabled by technologies such as online learning, Massive Open Online Courses (MOOCs), Small Private Online Courses (SPOCs), and Open Education Resources. As the modern university library's core mission has been impacted by these changes, it has responded in innovative ways. For example, many university libraries have spent time repurposing their physical space and expanding their reach online to support new pedagogies and changes in the teaching and research process. An example of such efforts may be found in the role of case studies programs inside the university library, which will be discussed below. However, the library as "place" or "space" is a theme that has inspired a great deal of discussion among library leaders, to which we now turn.

During many stages of the university library's history outlined above, many scholars asserted that the concept of a "virtual library," combined with the powers of the Internet, would eventually replace the physical library. The library as a place, it was argued, would no longer be a critical component of an academic institution (Kammerlocher et al., p. 393). For several generations, academic librarians were primarily preoccupied with the role of their library buildings as portals to print and, later, digital information. Recently, the same community has reevaluated their ingrained concept of place as central to the library and returned to the core of their mission: libraries are people. The patrons, faculty, students, staff - even the librarians themselves - are at the heart of what makes a library, and the physical 
space can and should be responsive to how these communities access and use information to learn and contribute to scholarship and participate fully in the academic life of the university. Today the university uses its contemporary understanding of place to embrace both the evolving role of the library and its earlier incarnation as a physical portal to information. Both of these understandings hold central the learning, culture, and intellectual community of its institution.

In the past, expanding collections reduced user space; now, just the opposite is true. Technology has enriched user space, and the services for its support are increasing at a much faster pace than ever anticipated. Libraries are willing to sacrifice traditional shelving and study carrels for space with new teaching, learning, and curriculum support staff, the required technology, and the rooms to hold both. While information technology has not replaced print media, and is not expected to do so in the foreseeable future, it nonetheless has had an astonishing and quite unanticipated impact on the role of the library. Contrary to the predictions of the diminishing relevance and eventual obsolescence of libraries, usage of electronic materials has expanded dramatically - sometimes double or even triple that of its print counterparts (Kammerlocher et al., p. 393). Collaborative space planning - not just run by the library, but also by teaching, learning, and curriculum department - has recently occurred over the last decade at the University of Southern California, Emory University, Dartmouth College, Fordham University, and Illinois Wesleyan University (Kammerlocher et al., p. 397). This innovative space planning has led to an increase in awareness of what the library can offer a university community, and, as a result, library usage increases. Rather than threatening the traditional concept of the library, the integration of new information technology has actually become a catalyst that has transformed the library into a more vital intellectual center of life at colleges and universities today.

The university library should be one of several locations on campus where new and emerging information technologies can be combined with traditional print resources in a usermotivated, library service-focused environment that supports the university's mission for learning, teaching, and research. As library architect Geoffrey T. Freeman states "Whereas the Internet has tended to isolate people, the library, as a physical place, has done just the 
opposite. Within the institution, as a reinvigorated, dynamic learning resource, the library can once again become the centerpiece for establishing the intellectual community and scholarly enterprise" (Kammerlocher et al., p. 394).

Much as the Internet provides 24/7 access to university library resources, any university libraries should provide $24 / 7$ access to its physical space as well. More often than not, the library still serves as a critical center for study and research. In some studies, faculty and staff have even preferred to study in the library. If you combine this $24 / 7$ access with critical services and technology that are located when and where the user needs it, then the university library will have met the needs of its diverse users in a responsive way.

The ubiquitous use of electronic databases, digitized content, and interactive media has also fostered a shift from independent study to more collaborative and interactive learning. $A$ student can go to the physical space called the "university library" and see it as an extension of the university classroom. For example, students, researchers, and faculty today explore information in a variety of formats, analyze the content in discussion groups, and produce a publication or a presentation for the next day's seminar. To address these needs, university libraries must provide a plethora of tech-enabled group study rooms and project development spaces. As "library laboratories that learn," these universities library spaces are designed to be easily reconfigured in response to new technologies and pedagogies.

One of the fastest growing movements, reflecting the university library as laboratory and library as university classroom is the makerspace movement. This movement, emerging from the DIY movement of the last decade, emphasizes the use of technology, most notably 3D printers, to drive learning, discussion, and self-starting scholarship. Makerspaces, also sometimes called hackerspaces, can be any area where people gather to make and create. In makerspaces, people share supplies, skills, and ideas, and often work together on projects. In general, university makerspace values a culture of creation over consumption. Many libraries have found that maker culture and makerspaces fit naturally with their existing missions and have begun to incorporate makerspaces into the services they offer their communities. 
Lisa Kurt, Emerging Technologies Librarian at the DeLaMare Library at the University of Nevada, Reno, said in a 2012 interview, "Faculty are teaching by going beyond testing and asking their students to create content beyond papers. We are seeing assignments asking students to create posters, presentations, videos, tutorials, various prototypes and models (not just from the 3D printer)" (Fisher, 2012). Again, the university library now often serves as an extension of the university classroom - one that is hosted and staffed by the university's information professionals who are often also tech savvy makers themselves. By bringing makerspaces into university libraries, librarians can adapt to changing student needs and support knowledge creation in addition to knowledge consumption.

Many different university libraries have adopted small, yet technologically advanced makerspace-like labs. The Innovation Lab \& Makerspace is part of Southern New Hampshire University's Shapiro Library and is open to faculty, students, and staff. Along with a wide array of tools, equipment, and software - ranging from 3D printers and Arduino kits to hammers and paintbrushes - the Innovation Lab \& Makerspace offers trainings and workshops to the academic community.

In this interactive learning environment, it is important to both accommodate the sound of learning - lively group discussions or conversations over coffee - while controlling the impact of that sound on surrounding space. University libraries must remain a place for both types of inquiry: lively group learning and dedicated, contemplative quiet zones. Both features of these learning styles remain an important aspect of any place of scholarship.

University libraries are finding creative ways to repurpose library spaces and make optimal budgeting choices. Not only has the makerspace movement driven this change, but the nature of interdisciplinary research at universities has caused many university libraries to consider repurposing to be a necessary element of a new library mission. In the past three years, 62.6 percent of academic libraries reported repurposing space for group study, student success areas (writing/tutoring centers), quiet study space, technology learning spaces, and additional seating. Doctoral/research institutions undertook the most renovations (79.5 percent), followed by baccalaureate schools (60.8 percent), comprehensive schools (65.1 
percent), and associate degree-granting institutions (47.3 percent). Within the next five years, 79 percent of doctoral/research institutions, 69 percent of comprehensive institutions, 65 percent of baccalaureate schools, and 45 percent of associate degree-granting institutions are planning additions, renovations, refurbishments, or new buildings. A recent survey found that 15.5 percent of academic libraries expect library space usage to increase significantly with 27.4 percent of doctoral/research institutions forecasting a significant increase (American Library Association, 2014b). Clearly, physical library space and its use continues to be intimately tied to the library's mission.

\section{Law and Policy in the University Library}

Another essential for a modern university library is a full understanding of the law regarding the relationship between libraries and copyright. Having a reliable point of contact for copyright law is a critical component of a successful twenty-first-century university library. To that end, the ALA lists copyright as a core competency of librarianship. There is an inherent tension in this environment, however: university librarians want to provide whatever their academic community may desire, but they also must balance the law against the user's needs. Fortunately, copyright law does not always restrict certain uses. In many cases a solid understanding of copyright can help ease fears, provide legal alternatives to a particular request, or help educate the university community at large. The next sub-section examines the university library through the lens of the law, specifically focusing on US copyright law.

In the United States, for example, the concept of the "library" as defined by Congress, affords libraries certain protections that are not available to the general public. While user cannot scan or digitize certain items because of copyright law, libraries may do so without fear of infringement or other penalties. Congressional authority has declared libraries "special," and in the world of digitization, a library's status allows for large-scale projects that will ensure both worldwide access and digital preservation - key components of any modern library mission.

\section{Library Exceptions (\$108)}

Section 108 of the US Copyright Act provides that under certain conditions it is not infringement for a library or archive, or its employees acting within the scope of their 
employment, to reproduce or distribute one copy of a work (or in particular cases, three

copies). There are very specific conditions in Section 108(a) that must be met to qualify for this exception. For example, library copies cannot be made for any direct or indirect commercial advantage; the library's collections must be open to the public, available to researchers affiliated with the library, or other persons doing research in a specialized field; and, last, the reproduction or distribution must include a notice of copyright or a statement that the work may be protected by copyright if no notice is found on the original.

The exceptions granted under section 108 extend only "to the isolated and unrelated reproduction or distribution of a single copy... of the same material on separate occasions" (US Copyright Office, 2011b) and do not apply to "a musical work, a pictorial, graphic or sculptural work, or a motion picture or other audiovisual work other than an audiovisual work dealing with news" (US Copyright Office, 2011b) Once a university library has met the requirements above, it can copy, scan, or distribute copies to the university community in certain circumstances. For example, replacement copies, preservation copies, user-requested copies, interlibrary loan, and copies of out-of-print works are all permitted by libraries under Section 108.

\section{First sale doctrine (§109)}

In the US one of the more important limitations on the exclusive right of a copyright holder is the first sale doctrine, which prevents an owner from controlling subsequent transfers of his or her works. The first sale doctrine is a fundamental law that allows university libraries to loan books to patrons. Once a copyright holder transfers ownership of a copy, she no longer has rights to that copy (US Copyright Office, 2011c).

Entire industries and enterprises are built upon the first sale doctrine. eBay relies on this provision when it permits users to sell copyrighted protected works through its site, and libraries are permitted to lend to patrons copies of printed books that they acquired, all without the requirement of a request for permission from the copyright owner. Without this law, copyright holders could enforce rights in the "secondary market," which would impact selling, loaning, or gifting any copyrighted work. The rationale is that "once the copyright owner places 
a copyrighted item in the stream of commerce by selling it, he has exhausted his exclusive statutory right to control its distribution" (Quality King Distributors, Inc. v. L'anza Research Intern., Inc., 1998).

In the digital context, although the first sale doctrine limits the copyright owner's distribution right, it does not affect the reproduction right. Electronic transmissions of a work are generally forbidden because of the nature of copies in today's digital environment. Files that are in .pdf format, for example, can allow a transfer from one party to another, but the transferor still may retain a perfect copy of the work. In 2001, the Register of Copyrights soundly rejected a recommendation to create a "digital first sale" doctrine, which would permit an owner of a digital work to transfer it to another person, provided that the original was deleted (Register of Copyright, 2001). This rejection, along with other developments of this law from its origin to the present day, makes it clear that Section 109 first sale rights mainly apply to physical, not digital, disposal of copies, at least for now.

\section{Fair Use (§107) and Best Practices}

Like the first sale doctrine, fair use is not specific to university libraries, but recent decisions by the US federal courts have determined that modern libraries are one of the most important guardians and users of this specific right. At its core, fair use ensures that there are some kinds of uses that do not require permission or payment, which provides flexibility for content users and creators. There are, however, no easy rules for fair use, and libraries should be taking the lead in copyright education on campus.

The source of fair use law is statutory: Section 107 of the Copyright Act provides that fair use of a work "for purposes such as criticism, comment, news reporting, teaching (including multiple copies for classroom use), scholarship, or research" (US Copyright Office, 2011a) is not copyright infringement. This list is not exhaustive; other uses of copyrighted work without permission may also be fair.

Section 107 of the Copyright Act provides: 
Notwithstanding the provisions of sections 106 and 106A, the fair use of a copyrighted work, including such use by reproduction in copies or phonorecords or by any other means specified by that section, for purposes such as criticism, comment, news reporting, teaching (including multiple copies for classroom use), scholarship, or research, is not an infringement of copyright. In determining whether the use made of a work in any particular case is a fair use the factors to be considered shall include-

(1) the purpose and character of the use, including whether such use is of a commercial nature or is for nonprofit educational purposes;

(2) the nature of the copyrighted work;

(3) the amount and substantiality of the portion used in relation to the copyrighted work as a whole; and

(4) the effect of the use upon the potential market for or value of the copyrighted work.

The fact that a work is unpublished shall not itself bar a finding of fair use if such finding is made upon consideration of all the above factors. (US Copyright Office, 2011a) In the university library context, this four factor test is also used up front for risk mitigation. For example, libraries frequently use this test to determine whether or not they can perform a certain activity or function involving copying or scanning. By reviewing the four factors, as a court might, a librarian can determine whether or not the action she is taking might risk infringement or fall squarely within the realm of fair use.

In recent years, US courts have focused increasingly on whether an alleged fair use is "transformative." A work is transformative if, in the words of the Supreme Court, it "adds something new, with a further purpose or different character, altering the first with new expression, meaning or message." Use of a quotation from an earlier work in a critical essay to illustrate the essayist's argument is a classic example of transformative use. Conversely, a use that supplants or substitutes for the original work is far less likely to be deemed a fair use than one that makes a new contribution.

In the last five years, there were some enormously positive developments in the realm of copyright, transformative fair use, and libraries. The US Court of Appeals for the Second Circuit upheld the ruling in Authors Guild v. HathiTrust, deciding that providing a full-text search database of scanned books is the same as providing access to these books for people with print disabilities, which constitutes a transformative fair use. HathiTrust has paved the way for 
university libraries to embrace activities such as text and data mining, which are now on the forefront of interdisciplinary research.

A similar case, Authors Guild, Inc. v. Google, Inc., found that Google did not infringe any copyright through its Google Book Search database, which shows "snippets" or significantly small portions of works from the millions of books that were scanned at many US university libraries. US Circuit Judge Denny Chin dismissed the lawsuit, and affirmed that the Google Books program meets all legal requirements for fair use. In 2014, the Authors Guild appealed the ruling to the US Second Circuit.

In October 2014, the US Court of Appeals for the Eleventh Circuit handed down an important decision in Cambridge University Press et al. v. Carl V. Patton et al. (frequently called the Georgia State University e-reserves case), which is now on appeal. This case was the first time in history that a university library was sued by a university publisher for an electronic reserves policy. Georgia State University relied exclusively on fair use to make its electronic reserves available to university students. The university publishers felt it was far beyond what fair use would allow, and demanded licensing. This decision emphasizes a thoughtful analysis of fair use and a rejection of the highly restrictive guidelines promoted by many publishers. While on appeal presently, the 300+ page lower court decision effectively dismissed the majority of the publisher's claims, and 95 percent of the works on electronic reserve were found to be fair use. Other university libraries should take note: a solid understanding of copyright may be one of the best risk mitigation activities it can undertake in this modern digital era.

Over the last decade, library codes of best practices have become common tools used by the community to mitigate risk for a host of civil and criminal wrongs, including fair use and copyright infringement. The term "best practices" has not been defined by case, statute, or regulation very well, and it has its origins in business management, not law. That said, there are some elements of them found in the law; the Uniform Commercial Code, for example, is an attempt to codify industry best practice.

These library best practices are usually compiled from the practices and values of a particular community's mission. While they are not law, they have the effect of defining what is "reasonable," so that if litigation does arise the courts can look to the best practices either as 
a form of a good faith effort or to alleviate some of the brunt of liability. Determining the minimum practices necessary to protect against potential liability will ultimately be decided on a case-by-case basis in a court of law.

These codes of best practice are useful as tool of education and risk mitigation, however, and serve as indicators of what is reasonable for a particular profession or work function. As a result of the rapid movement into the digital age, these best practices frequently have to do with university libraries and archives.

The Code of Best Practices for Fair Use in Academic and Research Libraries by Association of Research Libraries, the Center for Social Media, School of Communication, American University, and the Program on Information Justice and Intellectual Property, Washington College of Law, American University was devised specifically by and for the academic and research library community. It bolsters the ability of librarians to rely on fair use by documenting the considered views of their community about best practices in fair use, drawn from the actual experience of the library community itself (http://www.centerforsocialmedia.org/libraries).

\section{Library Innocent Infringer § 504(c)(2)}

Last, in the US, if a library is found guilty of infringing a copyrighted work, there is a potential chance that there will be no statutory damages for such infringement. Congress offers university libraries one last chance to avoid penalty in section 504(c)(2). This section states that if the infringer is a library or archive, or the employee of a library or archive, then the court can lower or eliminate damages altogether if the infringer "believed and had reasonable grounds for believing that his or her use of the copyrighted work was a fair use under § 107" (US Copyright Office, 2011d). To help support this in practice, a university library should try to retain any documentation used to determine that the alleged use was a fair use. Knowledge of this section can also aid the "total" analysis for risk mitigation of various university library activities.

\section{Open Access in the University Library}


We turn now from the library as content consumer to the library as content enabler and creator.

Motivated by a convergence of external stressors-reduced funding, soaring serials costs, and big deals (that is, "bundled online subscriptions to their entire list of academic journals at prices significantly lower than the sum of their á la carte prices"; Bergstrom, Courant, McAfee, \& Williams, 2014) (Kyrillidou, Morris, \& Roebuck, 2013)-academic libraries, in particular, have explored opportunities afforded by open access (OA) in a variety of ways. From establishing institutional repositories (IRs) and managing the implementation of their institution's complementary OA policies to launching journal and monograph publishing programs, academic libraries have seen the potential benefit of and growth opportunities afforded by pursuing OA initiatives. As we will detail below, these efforts have invigorated the traditional academic library into a nimble and responsive branch of the institution and communities it serves. Librarians, partnering with administrators, faculty, and others, have driven this effort to reimagine time-tested skills to meet the needs of the digital era user. The efforts of academic libraries in the OA movement are a nearly a decade old, and in this time substantial progress has been made and the momentum in this direction is expanding.

\section{The Institutional Repository}

In 2002, inspired by the efforts of those fields with a robust preprint repository culture, Raym Crow penned "The Case for Institutional Repositories," (Crow, 2002) which was a call to arms for institutions. Crow argued that if beset academic institutions created institution-specific repositories, then they would be in the position to both "reform the system of scholarly communication... [and] demonstrate the scientific, societal, and economic relevance of its research activities" (Crow, 2002). Around the same time, MIT launched its open-source repository DSpace and the University of California released its eScholarship Repository (Poynder, 2006). Other software solutions emerged, giving institutions choices in digital repository technology (including custom, open source, and vended solutions). A second article rallying institutions to adopt repositories was penned, this time by Clifford Lynch. Lynch posited, "the primary responsibility of our universities is to exercise stewardship over these riches ['the 
intellectual life and scholarship of our universities']: both to make them available and to preserve them" (Lynch, 2003). Thus, the stage was set for libraries to preserve their community's output with the newly available tools.

As the library established IRs, they have very often assumed the role of implementer and manager. The skills required to collect, maintain, and preserve institutional knowledge fall squarely into the academic library's wheelhouse. The very standards that make a repository functional to users, interoperable between institutions, and durable for future use are a library's strengths: collection, metadata creation and management, rights review and documentation, and access and preservation.

As natural a fit as IRs are to the academic library, the effort has been neither seamless nor straightforward. Following the implementation of repositories, library literature has reflected the field's evolving efforts to shift traditional functions into the digital realm. From detailing the challenges of ensuring metadata quality (Park, 2009; Chapman, Reynolds, \& Shreenes, 2009) to securing preservation (Li \& Banach, 2011) of content into the future, library professionals have actively engaged with new services around this technology to better understand the challenges inherent to the new digital environment and to develop best practices (Shieber \& Suber, 2015) for ensuring the success of IRs for authors and researchers today and into the future.

Perhaps the biggest challenge and growth area for today's libraries has been the collection of scholarship.

Perhaps the most noteworthy action taken by institutions to encourage author participation in populating work in the IR has been the passage of institutional OA policies and mandates (Open Access Directory, 2015b; MIT, Scholarly Publishing @ MIT Libraries, 2015b). As noted in "Good Practices for University Open-Access Policies":

Policies of this sort [i.e., those that provide "for automatic default rights retention in scholarly articles and a commitment to provide copies of articles for open distribution"] have many benefits: they allow authors to retain extremely broad use and reuse rights with a minimum of effort; they allow universities to help authors in openly distributing articles for maximum impact; they allow other researchers and the general public to obtain broader access to articles; all while preserving academic freedom, author choice, and consistency with copyright and other law. (Shieber \& Suber, 2015) 
Even in light of faculty-approved policies a recent survey of IR growth rate indicated that, "The rising amount of faculty content in IRs indicates faculty are increasingly willing to participate in the IR...[however, their] involvement may be more passive than active" (Dubinsky, 2014) Because academic libraries are often tasked with managing the implementation of their parent institution's OA policy, they have met the challenges presented by this new technology in innovative ways, which has encouraged creative solutions and collaboration. Doing so takes many forms.

By leveraging metadata standards, such as OAI-PMH (Open Archives.org, 2015), coupled with protocols for depositing content, such as SWORD (see http://swordapp.org/), to repositories, academic librarians have streamlined automated deposit, so content that authors have deposited in one repository may be harvested by another, along with publisher content and other content sources, increasing the work's readership with little friction on the author's part (Lewis, de Castro, \& Jones, 2012). A plethora of tools to similarly automate deposit have emerged (Shieber \& Suber, 2015), empowering libraries at institutions with fewer resources with alternatives to the ever-challenging faculty self-archiving or labor-intensive librarymediated deposit.

Similarly, academic libraries have worked to increase buy-in by making the process easier and more appealing for faculty. From integrating deposit with the author's workflow (for example, using Zotero to deposit work to an IR; Grigor, 2014), employing students to deposit work on a faculty member's behalf (Openbiomed.info, 2011), and personalizing services within the IR and in outreach efforts (Shieber \& Suber, 2015), academic librarians have worked to lower the bar and encourage faculty participation in this new tool, which will ultimately benefit their work.

Last, academic libraries have made efforts to incentivize participation in IRs by implementing value-added features for authors. Download metrics proved to be particularly powerful evidence of a work's increased readership, and altmetrics (Priem, Taraborelli, Groth, \& Neylon, 2010) are now often available in IRs, further showcasing the life of a work (Konkiel \& Scherer, 2013). In an effort to provide more qualitative evidence of IR use, some institutions 
have started to collect stories from IR users (MIT, Scholarly Publishing @ MIT Libraries, 2015a; Harvard University, Office for Scholarly Communication, 2015).

This very limited history and sampling of repositories and the library's role in encouraging participation in this particular OA effort is meant to illustrate the ways in which academic librarians have recast their roles as catalogers, digital technologists, and outreach liaisons to ensure institutional participation in OA activities. Whether an academic institution has funding for a formalized scholarly communication office with staff that are specialized to meet the technological, intellectual property, and outreach needs of the community, or librarians from across the organization assume new responsibilities in their roles to support the $I R$, there is innovation happening in the name of OA.

IRs represent an opportunity for libraries to collect their institution's scholarship and share this wealth with a global audience in ways not previously imagined. From dissertations to data, images to peer-reviewed articles, IRs are opening author's scholarship to a previously invisible audience and delivering content to readers that would otherwise not be able to access it. By collecting and preserving institutional output in a robust, systematic way, IRs are ensuring that the power of the web is being used to improve the way in which scholarship is created, shared, and stored.

The future continues to look bright as data integration and annotation tools are making their way into repository space too, expanding services to both authors and readers. Librarians are at the fore of this effort, using new technology and time-tested practices to ensure the academic library's mission is operating at the pace it should in the digital era.

\section{Open Access and Library Publishing}

As noted above, library budgets consistently have been squeezed, with 69 percent of academic libraries reporting decreases in budgets for the current fiscal year and 22 percent of these institutions expecting an additional decrease for the coming year (Bosch \& Henderson, 2012). Coupled with this challenging reality, journal prices continue to increase consistently, 
and "half of the titles in the combined indexes are from five major publishers-Elsevier, Wiley, Springer, Taylor \& Francis, and Sage" (Bosch \& Henderson, 2012).

In response OA journal projects emerged in the marketplace, and much as IRs have gained a foothold in the past several years, so too have these OA journals made interesting, creative inroads, offering authors exciting opportunities and alternatives. By the numbers, there are 10,258 OA journals listed in the DOAJ (see http://doaj.org). Of these, "[a] small number of publishers...published a relatively high proportion of all DOAJ journals," with university publishers accounting for 32 percent of the journals in different subject categories (Walters \& Linvill, 2011).

As more titles appear on the market each year concerns have been raised about legitimacy and quality (Bohannon, 2013; Suber, 2013). Armed with subject expertise, an intimate knowledge of the publishing lifecycle and players in it, and tools that help to winnow down potential titles, librarians are well suited to help authors find appropriate venues for their research in legitimate OA journals (Berger \& Cirasella, 2015).

In addition to helping dispel myths surrounding OA journals, libraries have entered the OA publishing marketplace with gusto. As they have started to do so, it is interesting to consider why and how are they launching OA projects, and what these efforts offer. A 2008 report by Karla Hahn, "Research Library Publishing Services: New Options for University Publishing" finds that library publishing programs include both new and established titles, which rely on campus partnerships and span disciplines. The size of these publishing efforts varies, as do the levels of service, staffing, and budget.

Whether a library's publishing program is more modest, offering simple hosting solutions, or more active in soliciting titles and marketing a suite of services (from copyediting to securing DOIs), research has found that these institutions all feel "libraries should be involved in journal hosting and publishing" (Maughan Perry, Borchert, Deliyannides, Kosavic, \& Kennison, 2011).

Why? As publishing has become more constrained with the consolidation of publishers, there are real gaps in the landscape for scholars and researchers. As an article in The Chronicle of Higher Education on library publishing notes, "What it [library publishing] can do now is 
'open up the niches' and bring attention to scholarship that might otherwise be overlooked...'That's still the most important reason libraries should be involved in publishingto do what we can to help promote research on the campus'" (Howard, 2013). Furthermore, providing in-house support for such OA publishing efforts affords greater flexibility for authors, expands the services the library provides to its community, and ensures that critical scholarship is finding as broad an audience as possible.

As with repositories, a suite of technical solutions has emerged for those libraries interested in hosting an OA journals program (Open Access Directory, 2015a). Some libraries are using stand-alone publishing platforms, while others have integrated journal publishing efforts with their IR. This has lowered the barrier for institutions that may not have the technical skill to create custom journal-hosting platforms. Similarly, library publishing best practices (Mullins et al., 2012) and a membership community (see www.librarypublishing.org) have emerged, which have helped to both scaffold current practice and formalize library-based publishing efforts by creating a shared discussion space.

Much as librarians have leveraged their skill set in support of IRs, they have also done so with OA publishing efforts. Collection development and cataloging skills, coupled with outreach efforts and an intimate understanding of the scholarly publishing ecosystem, serve librarybased publishing programs. As such, these efforts can better support author scholarship and author rights and ensure the widest possible access the broadest audience.

Perhaps the most powerful advantage these library-based publishing efforts provide to authors is that smaller and emerging fields, whose scholarship might not otherwise have been published, finds a home. As noted in an article by J.-G. Bankier and I. Perciali (2008), "By supporting such journals [i.e., those that may not be 'a good fit for a commercial publishing house'], the university offers a tremendous service to its faculty, and a great benefit to the research community at large."

Even more interesting are new journal publishing models with which academic libraries are experimenting. Recently, Dartmouth, the Georgia Institute of Technology, the University of Colorado Boulder, the University of Michigan, and the University of Washington partnered with BioOne to release Elementa: Science of the Anthropocene (see www.elementascience.org/). 
This collaboration has resulted in a high-quality, highly functional journal that includes six subject domains in one publication, branded as a single entity. While it is still early days, this exciting venture exemplifies the innovation potential that library-based publishing holds. With creative funding and novel approaches, library publishing can offer authors a publishing experience that meets their needs with greater flexibility and control, and readers access to more quality scholarship.

\section{Case Studies in the Library}

Last, the collaborative twenty-first-century research environment described in the various topics above demands a dramatic shift in the university libraries to serve the needs of

their teaching community. The birth of case study programs inside libraries is significant; they tie together the concepts of collection, space, publication, law, and open access.

Case-driven methods of teaching and learning are hundreds of year old, but their use and availability have been limited in the past. The successes and the challenges of such a program, from the vantage point of the expertise that library information professionals bring to a curriculum, can help drive further discussions about advances in technology that enable new methods for library delivery and access.

By way of example, Harvard Law School (HLS) moved their case writing program into the Law Library in 2012. The dean wanted to put case studies in a department that did not already produce its own cases so that it would not favor any one department/research center. The Harvard Law School Library (HLSL) offered the infrastructure to help carry the load without requiring additional administrative expenses. The result was the new "Case Studies Program" (http://casestudies.law.harvard.edu).

The Case Studies Program creates a central portal for all the case study and experiential teaching materials developed at HLS, including interactive case studies, role plays, and problem sets developed for the JD program, executive education courses, and courses through the Program on Negotiation (PON). Educators, students, and staff at degree-granting institutions can view free educator copies and purchase teaching materials. The general public and for- 
profit entities may also view and purchase materials from this website. This newly centralized case studies program is operated by HLSL.

The Case Study Program resources are written by HLS or PON faculty, staff, or graduate research fellows. In some cases, the case study website offers cases written by HLS- or PONaffiliated authors that are extensively tested and endorsed by an HLS or PON faculty member. The HLSL Case Studies staff works closely with the faculty members to develop each case. Interviews, research, editing, and drafts are carefully reviewed and vetted by library staff at each stage, and put into production through the law library's Case Study Program website.

From the point of view of the library, this was a natural fit. Modern university librarians are trained to research. They have advanced technical skills beyond that of the faculty. Additionally, they often have a good understanding of teaching and pedagogy. These combined skills are a perfect complement to a case study program. Librarians can help with content creation, research, and teaching, and they have the technological skills to aid with the uploading and organization of the delivery systems.

Additionally, having the case studies program in a university library can strengthen ties with the faculty, who, as we know, are often the real drivers of research, scholarship, and collections at any university library. HLSL has strengthened their relationship with faculty members through the Case Studies Program. There is an awareness that HLSL can help produce new cases and that they are aligned with both the unique teaching mission and traditional research of the Harvard Law School. Relationships like these can help build further political capital needed to help a university library maintain its importance in the community.

It is true that such programs inevitably require staffing, but, as Suzanne Wones, Executive Director of the Harvard Law Library states, moving a case studies program into HLSL "has added some work to the library, mostly in the new positions created to support the program, but also in some additional existing positions have naturally found their fit in the program. There have also been some cases that have led to support by the reference librarians. That is work we always would have done, but the faculty members might not have thought to ask without prompting by the Case Studies staff." 
Library-centric case studies programs like these have often adopted free or low-cost policies for their cases. In many cases, HLSL Case Studies are absolutely free. With the influence from their university library, other case study programs may choose to adopt OA policies for their cases and distribute them openly in their institution's repository. This is often directly in line with the mission of the university - to provide expanded dissemination of research and scholarship in a way that leverages digital networked technology free of excessive rights or financial burdens. Case studies themselves are meant to be shared, adopted, and taught at other institutions, helping to spread the "hands on" method of teaching. University libraries, again, should be on the forefront of such movements as the natural leaders in this sphere.

In all measures, the Case Studies Program has experienced growth since its move into HLSL: in unique website hits, in orders, customers, downloads, and revenue. Their global customers express appreciation that they provide these case study materials on the library website.

\section{Conclusion}

The demand for services and technological access to information at a university library, regardless of format, is growing exponentially. In response, the university library must adopt a new perspective and understanding if it is to fulfill its potential in adding value to the advancement of the university's mission. By marrying the traditional print and physical space of the past with the new information technology and pedagogical place of the future with responsive and innovative services, the university library will continue to thrive in this new digital age. Moving an institution into the future in no small task. However, we are in an era of evolution for university libraries, which, if responsive to their community's expanding needs, will maintain their place at the heart of their institution. The special place university libraries have traditionally held in law, policy, and pedagogy, will only help to drive the expansion of programs reflective of the university mission. The university library is now poised to be on the forefront of the twenty-first-century digital movement as it harnesses its staff, collections, and expertise to provide next-generation support for research, teaching, technology, and access. 
Alston Jones, Jr., Plummer. (1989).The history and development of libraries in American higher education. College and Research Libraries News, 50, 561-564.

American Library Association. (2014a, July 1). Diversity in collection development: An interpretation of the Library Bill of Rights. Adopted July 14, 1982, by the ALA Council; amended January 10, 1990; July 2, 2008; and July 1, 2014. Retrieved from http://www.ala.org/advocacy/intfreedom/librarybill/interpretations/diversitycollection.

American Library Association. (2014b). State of America's libraries report. Retrieved from http://www.ala.org/news/state-americas-libraries-report-2014.

American Library Association, Interlibrary Loan Committee, Reference and User Services Association. (2008). Interlibrary Loan Code for the United States. Prepared by the Interlibrary Loan Committee, Reference and User Services Association (RUSA), 1994, revised 2001. Revised 2008, by the Sharing and Transforming Access to Resources Section (STARS). Retrieved from http://www.ala.org/rusa/resources/guidelines/interlibrary.

Arougheti, Stephen. (2014). Keeping up with...Patron driven acquisitions. Retrieved from http://www.ala.org/acrl/publications/keeping_up_with/pda.

Atkinson, Richard C., \& Blanpied, William A. (2008). Research universities: Core of the US science and technology system. Technology in Society, 30, 30-40.

doi:10.1016/j.techsoc.2007.10.004

Bankier, Jean-Gabriel, \& Perciali, Irene. (2008). The institutional repository rediscovered: What can a university do for open access publishing. Research on Institutional Repositories: Articles and Presentations, Paper 29. Retrieved from http://digitalcommons.bepress.com/repositoryresearch/29.

Berger, Monica, \& Cirasella, Jill. (2015). Beyond Beall's list: Better understanding predatory publishers. College \& Research Libraries News, 76(3), 132-135.

http://crln.acrl.org/content/76/3/132

Bergstrom, Theodore C., Courant, Paul N., McAfee, R. Preston, \& Williams. Michael A. (2014). Evaluating big deal journal bundles. PNAS, 111(26), 9425-9430. doi:10.1073/pnas.1403006111

Bohannon, John.(2013). Who's afraid of peer review? Science, 342(6154) 60-65.

doi:10.1126/science.342.6154.60

Bosch, Stephen, \& Henderson, Kittie. (2012, April 30). Coping with the terrible twins: Periodicals price survey 2012. Library Journal. Retrieved from 
http://lj.libraryjournal.com/2012/04/funding/coping-with-the-terrible-twins-periodicals-pricesurvey-2012/\#_.

Bushing, Mary C. (2001). The evolution of Conspectus practice in libraries: The beginnings and the present applications. Proceedings of CASLIN, 2001: Document Description and Access: New Challenges, Beroun, Czech Republic. Retrieved from http://klement.nkp.cz/Caslin/caslin01/sbornik/conspectus.html.

Chapman, John W., Reynolds, David, \& Shreeves, Sarah A. (2009). Repository metadata: Approaches and challenges. Cataloging \& Classification Quarterly, 47(3-4), 309-325. doi:10.1080/01639370902735020

Chung Wilson, Myoung, \& Edelman, Henrink. (1996). Collection development in an interdisciplinary context. The Journal of Academic Librarianship, 22(3) 195-200. doi:10.1016/S0099-1333(96)90058-0

Crow, Raym. (2002). The case for institutional repositories: A SPARC Position Paper. ARL Bimonthly Report, 223. Retrieved from http://www.sparc.arl.org/sites/default/files/media_files/instrepo.pdf.

Dubinsky, Ellen. (2014). A current snapshot of institutional repositories: Growth rate, disciplinary content and faculty contributions. Journal of Librarianship and Scholarly Communication, 2(3). doi:10.7710/2162-3309.1167

Dunlap, Leslie W. (1972). Readings in Library History. New York: R.R. Bowker. Fisher, Erin. (2012, November 28). Makerspaces move into academic libraries. ACRL Tech Connect. Retrieved from http://acrl.ala.org/techconnect/?p=2340.

Grigor, Catherine. (2014, April 15). Penn State awarded Mellon grant to study personal scholarly archiving. Penn State News. Retrieved from http://news.psu.edu/story/312098/2014/04/15/academics/penn-state-awarded-mellon-grantstudy-personal-scholarly-archiving.

Grover, Robert J., Gerre, Roger, C., Achleitner, Herbert K., \& Visnak, Kelly. (2015). Evolving global information infrastructure and information transfer. Santa Barbara, CA: Libraries Unlimited.

Harris, Michael H., \& Johnson, Elmer D. (1984). History of libraries in the Western World. Metchuen, NJ: Scarecrow.

Harvard University, Office for Scholarly Communication. (2015). Your story matters. Retrieved from https://osc.hul.harvard.edu/dash/stories. 
Howard, Jennifer. (2013, February 4). For new ideas in scholarly publishing, look to the library. The Chronicle of Higher Education. Retrieved from http://chronicle.com/article/Hot-Off-theLibrary-Press/136973/.

Johnson, Peggy. (2004). Fundamentals of collection development and management. Chicago, IL: American Library Association.

Jones, Douglas. (2011). On-demand information delivery: Integration of patron-driven acquisition into a comprehensive information delivery system. Journal of Library Administration 51(7-8), 764-767. doi:10.1080/01930826.2011.601275

Kammerlocher, Lisa, Couture, Juliann, Sparks, Olivia, Harp, Matthew, \& Allgood, Tammy. (2011). Information literacy in learning landscapes: Flexible, adaptable, low-cost solutions. Reference Services Review, 39(3), 390-400. doi:10.1108/00907321111161395

Konkiel, Stacy, \& Scherer, Dave. (2013). New opportunities for repositories in the age of altmetrics. ASIS\&T Bulletin, April/May. Retrieved from https://asis.org/Bulletin/Apr13/AprMay13_Konkiel_Scherer.html.

Kyrillidou, Martha, Morris, Shaneka, \& Roebuck, Gary. (2013). ARL statistics 2011-2012. ARL. Retrieved from http://www.arl.org/focus-areas/statistics-assessment/statisticaltrends\#.VOoTS7PF_7c.

Lewis, Stuart, de Castro, Pablo, \& Jones, Richard. (2012). SWORD: Facilitating deposit scenarios. D-Lib Magazine, 18(1/2). doi:10.1045/january2012-lewis

Li, Yuan, \& Banach, Meghan. (2011). Institutional repositories and digital preservation: Assessing current practices at research libraries. D-Lib Magazine, 17(5/6). doi:10.1045/may2011-yuanli

Lynch, Clifford A. (2003, February). Institutional repositories: Essential infrastructure for scholarship in the digital age. ARL, 226. Retrieved from http://works.bepress.com/ir_research/27/.

Martin, Susan K., \& Bosseau, Don L. (1996). Organizing collections within the Internet: A vision for access. The Journal of Academic Librarianship, 22(4), 291.

Maughan Perry, Anali, Borchert, Carol Ann, Deliyannides, Timothy S., Kosavic, Andrea, \& Kennison, Rebecca. (2011). Libraries as journal publishers. Serials Review, 37(3), 196-204. doi:10.1016/j.serrev.2011.06.00

MIT, Scholarly Publishing @ MIT Libraries, (2015a). Readers share their stories: Comments on open access articles. Retrieved from http://libraries.mit.edu/scholarly/comments-on-openaccess-articles/. 
MIT, Scholarly Publishing @ MIT Libraries, (2015b). Research funder policies and related legislation. Retrieved from http://libraries.mit.edu/scholarly/publishing/research-funders/.

Mullins, James L., Murray-Rust, Catherine, Ogburn, Joyce L., Crow, Raym, Ivins, October, Mower, Allyson, Nesdill, Daureen, Newton, Mark, Speer, Julie, \& Watkinson, Charles. (2012). Library publishing services: Strategies for success. Final research report. Washington, DC: SPARC. Retrieved from http://docs.lib.purdue.edu/purduepress_ebooks/24/.

Open Access Directory. (2015a, March 10) Free and open-source journal management software. Retrieved from http://oad.simmons.edu/oadwiki/Free_and_opensource_journal_management_software.

Open Access Directory. (2015b, July 3). Unanimous faculty votes. Retrieved from http://oad.simmons.edu/oadwiki/Unanimous_faculty_votes.

Open Archives.org. (2015, January 8). The Open Archives Initiative Protocol for Metadata Harvesting. Protocol Version 2.0 of 2002-06-14. Retrieved from http://www.openarchives.org/OAl/2.0/openarchivesprotocol.htm.

Openbiomed.info. (2011, June 4). Open Access Fellows (students) facilitate DASH deposits at Harvard. Retrieved from http://openbiomed.info/2011/06/oa-fellows-harvard/.

Palais, Elliot. (1987). Use of course analysis in compiling a collection development statement for a university library. The Journal of Academic Librarianship 13(1), 8-13.

Park, Jung-Ran. (2009). Metadata quality in digital repositories: A survey of the current state of the art. Cataloging \& Classification Quarterly, 47(3-4), 213-228.

doi:10.1080/01639370902737240

Pelish, Matthew. (2011). Redefining the academic library: Managing the migration to digital information services. Washington, DC: Education Advisory Board.

Poynder, Richard. (2006, March 1). Institutional repositories, and a little experiment. Retrieved from http://poynder.blogspot.com/2006/03/institutional-repositories-and-little.html.

Priem, Jason, Taraborelli, Dario, Groth, Paul, \& Neylon, Cameron. (2010, October 26). Altmetrics: A manifesto. Retrieved from http://altmetrics.org/manifesto.

Pritchard, Susan M. (2008). Deconstructing the library: Reconceptualizing collections, spaces and services. Journal of Academic Librarianship 48(2), 219-233.

doi:10.1080/01930820802231492 
Quality King Distributors, Inc. v. L'anza Research Intern., Inc., 523 U.S. 135, 152 (1998).

Retrieved from https://h2o.law.harvard.edu/cases/2344.

Register of Copyright. (2001). Digital Millennium Copyright Act Section 104 Report. Washington D.C.: U.S. Copyright Office. Retrieved from

http://www.copyright.gov/reports/studies/dmca/sec-104-report-vol-1.pdf.

Rubin, Richard E. (2010). Foundations of library and information science. New York, London: Neal-Schuman Publishers.

Sandler, Mark. (2006). Collection development in the age day of Google. Library Resources \& Technical Services 50(4), 239-243.

Schamber, Linda. (1996, April). Library Collection Development in an Electronic Age. ERIC Digest ED392467. Retrieved from http://www.ericdigests.org/1996-4/library.htm.

Shera, Jesse H. (1976). Introduction to library science: Basic elements of library service. Littleton, CO: Libraries Unlimited.

Shieber, Stuart, \& Suber, Peter. (2015, September 21). Good practices for university open-access policies. Berkman Center for Internet \& Society. Retrieved from http://cyber.law.harvard.edu/hoap/Good_practices_for_university_open-access_policies.

Suber, Peter. (2013, October 3). New "sting" of weak open-access journals. Retrieved from https://plus.google.com/u/0/+PeterSuber/posts/CRHeCAtQqGq.

Shreeves, Edward. (2003). Selectors, subject knowledge, and digital collections. Journal of Library Administration 39(4), 65-78. Retrieved from

http://www.tandfonline.com/doi/abs/10.1300/J111v39n04_07.

US Copyright Office, (2011a). Copyright Law of the United States of America, Section 107: Limitations on exclusive rights: Fair use. Retrieved from http://www.copyright.gov/title17/92chap1.html\#107.

US Copyright Office, (2011b). Copyright Law of the United States of America, Section 108: Limitations on exclusive rights: Reproduction by libraries and archives. Retrieved from http://www.copyright.gov/title17/92chap1.html\#108.

US Copyright Office, (2011c). Copyright Law of the United States of America, Section 109: Limitations on exclusive rights: Effect of transfer of particular copy or phonorecord. Retrieved from http://www.copyright.gov/title17/92chap1.html\#109. 
US Copyright Office, (2011d). Copyright Law of the United States of America, Section 504:

Remedies for infringement: Damages and profits. Retrieved from

http://www.copyright.gov/title17/92chap5.html\#504.

Walker, Kizer. (2012). Patron-driven acquisition in U.S. academic research libraries:

At the tipping point in 2011? Bibliothek Forschung und Praxis 36(1), 125-129. doi:10.1515/bfp2012-0015

Walters, William H. \& Linvill, Anne. (2011). Characteristics of open access journals in six subject areas. College \& Research Libraries, 72(4), 372-392. doi:10.5860/crl-132

Weiner, Sharon Gray. (2005). The history of academic libraries in the United States: A review of the literature. Library Philosophy and Practice, 7(2), Paper 58. Retrieved from http://digitalcommons.unl.edu/libphilprac/58. 